\title{
Farklı sıcaklıkların Leptinotarsa decemlineata (Say.) (Coleoptera: Chrysomelidae)'nın beslenme miktarı üzerine etkisi
}

\author{
Effect of different temperatures on the amount of feeding on Leptinotarsa \\ decemlineata (Say.) (Coleoptera: Chrysomelidae)
}

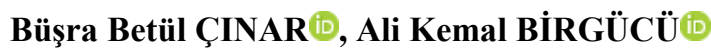 \\ Isparta Uygulamalı Bilimler Üniversitesi, Ziraat Fakültesi, Bitki Koruma Bölümü, 32260, Isparta, Türkiye \\ Sorumlu yazar (Corresponding author): A. K. Birgücü, e-posta (e-mail): alibirgucu@isparta.edu.tr \\ Yazar(lar) e-posta (Authore-mail): busrabetulcinar@gmail.com
}

\section{MAKALE BİLGİSI}

Alınış tarihi 11 Aralık 2020

Düzeltilme tarihi 08 Şubat 2021

Kabul tarihi 11 Subat 2021

\section{Anahtar Kelimeler:}

Beslenme

Ekoloji

Logan-10

Modelleme

Patates böceği

\begin{abstract}
ÖZ
Bu çalışmada Leptinotarsa decemlineata (Say.) (Coleoptera: Chrysomelidae)'nın beslenme miktarına sıcaklığın etkisi araştırılmıştır. Sıcaklığın zararlının beslenme miktarı üzerine etkisi, Logan-10 modeli kullanılarak açıklanmıştır. Bu amaçla, patates bitkisinden alınan yapraklı dal parçası, zararlının 24 saatlik beslenmesinden önce ve sonra tartılarak eksilen ağırlık miktarı belirlenmiștir. Aynı koșullarda yapraklı dal parçasının 24 saat içerisindeki su kaybı miktarı da belirlenmiş ve zararlının net tüketim miktarı hesaplanmıştır. Denemeler $2^{\circ} \mathrm{C}$ 'lik artışlarla $17^{\circ} \mathrm{C}$ ile $35^{\circ} \mathrm{C}$ arasında olacak șekilde 10 farklı sıcaklıkta gerçekleștirilmiștir. Elde edilen sonuçlara göre zararlının en yüksek tüketim miktarı $1507.10 \mathrm{mg}$ olarak $29^{\circ} \mathrm{C}$ 'de II. dönem larvalarda ve en düşük tüketim miktarı $199.80 \mathrm{mg}$ olarak $17^{\circ} \mathrm{C}$ 'de $\mathrm{IV}$. dönem larvalarda görülmüştür. Ayrıca zararlının tüketim miktarları üzerine uygulanan Logan-10 modeli eğrisine ve parametrelerine göre, zararlının tükettiği patates bitkisinin yapraklı dal parçası miktarı, belli bir sıcaklığa kadar artıș göstermiș ve optimum sıcaklığa $\left(27.99-28.81^{\circ} \mathrm{C}\right)$ ulaștıktan sonra tüketim miktarının azalarak sıfıra kadar $\left(37.18-37.87^{\circ} \mathrm{C}\right)$ düştüğü belirlenmiştir. Bu çalışma sonucunda, zararlının beslenme miktarı üzerine hem biyolojik dönemin hem de sıcaklığın doğrusal olmayan bir etkiye sahip olduğunu söylemek mümkündür. Ayrıca zararlının popülasyonundaki ve zarar miktarındaki mevsimsel değişimler ve dolayısıyla bu zararlıya karşı uygulanacak mücadele yöntemleri üzerine yapılacak ileriki çalışmalar için önemli verilerin elde edildiği düşünülmektedir.
\end{abstract}

\section{ARTICLE INFO}

Received 11 December 2020

Received in revised form 08 February 2021

Accepted 11 February 2021

\section{Keywords:}

Feeding

Ecology

Logan-10

Modelling

Colorado potato beetle

\begin{abstract}
The study aimed to investigate the effect of temperature on the feeding amount of Leptinotarsa decemlineata (Say.) (Coleoptera: Chrysomelidae). The effect of temperature on the feeding amount of the pest was explained using the Logan-10 model. For this purpose, the weight loss was determined by weighing the leafy branch piece taken from the potato plant, before and after the 24-hour feeding of the pest. At the same conditions, the amount of 24-hour water loss of the leafy branch was also determined and the net consumption amount was calculated. The experiments were carried out at 10 different temperatures between $17^{\circ} \mathrm{C}$ and $35^{\circ} \mathrm{C}$ in $2^{\circ} \mathrm{C}$ increments. According to the results obtained, the highest consumption amount of the pest was seen as $1507.10 \mathrm{mg}$ at $29^{\circ} \mathrm{C}$ in the second instar larvae, and the lowest consumption amount was seen as $199.80 \mathrm{mg}$ at $17^{\circ} \mathrm{C}$ in the fourth instar larvae. Besides, the Logan-10 model curve fitted to the consumption amounts of the leafy branches by the pest and its parameters showed that the consumption increased up to a certain temperature and decreased to zero $\left(37.18-37.87^{\circ} \mathrm{C}\right)$ after reaching the optimum temperature $\left(27.99-28.81^{\circ} \mathrm{C}\right)$. As a result, it is possible to say that both biological stage and temperature have a non-linear effect on the feeding amount of the pest. Also, it is thought that important data was obtained for future studies on the seasonal change in the population, and the damage amount of the pest, and therefore the methods of controlling to be applied against this pest.
\end{abstract}




\section{Giriş}

Patates böceği, Leptinotarsa decemlineata (Say.) (Coleoptera: Chrysomelidae)'nın ana vatanı Güneybatı Amerika ve Meksika'dır. Zararlıyı ilk olarak 1824 yılında Thomas Say isimlendirmiştir (Kekillioğlu ve Yılmaz 2018). Zararlının Türkiye'ye ilk olarak 1963 yılında Edirne ilinden giriş yaptığı bildirilmiștir (Atak 1973). L. decemlineata polifag bir zararlı olup ana konukçusu patates (Solanum tuberosum L.) bitkisidir (Çam ve ark. 2012) ve patates bitkisinin en önemli zararlılarından birisidir (Yabaş ve ark. 1995). Leptinotarsa cinsine bağlı $L$. decemlineata türü, Solanaceae familyasından en az 10 yabani ve kültür bitkisi türleri ile beslenen en geniş konukçu aralığına sahip bir türüdür (Kostik ve ark. 2016). Patates, besin değeri açısından, yumrusu yenen önemli bir sebze bitkisidir. Ülkemizde patates ekim alanları önceki yıllara göre azalmış ve 2018 yılında ise 136 hektar alan patates tarımı için kullanılmıştır. Ülkemizde patates üretimi yapılan 2018 yılı verilerine göre 71 ilimizde 4.55 milyon ton patates üretilmiş olup bunun 493 tonu tatlı patates çeşididir (TÜİK 2019).

Böceklerin farklı biyolojik dönemlerindeki bireyleri, konukçuları üzerinde farklı miktarlarda beslenebilirler. Nezara viridula (L.) (Hemiptera: Pentatomidae)'nın farklı biyolojik dönemlerinin fasulye baklasındaki zarar miktarı, en çok V. nimf döneminde ve en az zarar miktarını ise IV. nimf döneminde gerçekleşmiştir (Birgücü ve Karsavuran 2013). Ferro ve ark. (1985) ise yaptıkları bir çalışmada optimum koşullarda $\left(28^{\circ} \mathrm{C}\right)$ $L$. decemlineata'nın biyolojik dönemler içerisinde IV. dönem larvaların en yüksek beslenme miktarına sahip olduğunu bildirmişlerdir. Ayrıca $15^{\circ} \mathrm{C}$ 'de de yine IV. dönem larvaların en yüksek beslenme miktarını yaptığı ve bu dönemi ergin dönemdeki bireylerin takip ettiğini gözlemlemişlerdir. Noronha ve Cloutier (2006) ise yaptıkları bir çalışmada zararlının özellikle $17^{\circ} \mathrm{C}$ sıcaklıkta yaşlı yaprakları daha hızlı tükettiğini belirtmişlerdir. L. decemlineata larvaları Solanum tuberosum'a göre $S$. berthaultii üzerinde daha uzun süre gezinmişler ve daha az beslenmişlerdir (Neal ve ark. 1991). Dolezal ve ark. (2007) ise $L$. decemlineata larvalarının uzun gün koşullarında (18 saat aydınlık, 6 saat karanlık) kısa gün koşullarına (12 saat aydınlık, 12 saat karanlık) göre daha hızlı geliştiğini ve daha az yiyecek tüketmiş olduğunu bildirmişlerdir. Ayrıca böceğin beslenme miktarında bazı koşullara göre değişiklikler gözlemlenmiştir. Bunlar zararlının biyolojik dönemine, uzun gün-kısa gün zaman aralığına göre ve sicaklığa bağlı olarak beslenme miktarlarındaki değişimlerdir.

$\mathrm{Bu}$ çalışmanın asıl amacı, $L$. decemlineata'nın farklı biyolojik dönemlerindeki beslenme miktarlarına sıcaklığın etkisini belirlemek olmuştur. $\mathrm{Bu}$ kapsamda böceğin hangi sıcaklıklarda ve hangi biyolojik döneminde daha fazla miktarda beslendiği incelenmiştir. Bunun yanı sıra sıcaklığın zararlı böceğin farklı biyolojik dönemlerindeki beslenme miktarları üzerine etkisi, Logan-10 matematiksel modellemesi kullanılarak açıklanmıştır. $\mathrm{Bu}$ çalışma aynı zamanda buna benzer çalışmaların ilk basamağı niteliğinde olmuştur. Ayrıca ileride yapılacak çalışmalar için önemli veriler elde edilmiş ve zararlı ile mücadele yöntemlerine yönelik daha ileri ki çalışmaların kullanımı için bazı veriler ortaya koymuştur.

\section{Materyal ve Yöntem}

\subsection{Denemelerin kurulması}

Isparta Uygulamalı Bilimler Üniversitesi, Ziraat Fakültesi uygulama alanından $\left(37^{\circ}, 83^{\prime}, 52^{\prime \prime} \mathrm{K} ; 30^{\circ} .53^{\prime}, 69^{\prime \prime} \mathrm{D}\right)$ toplanan
L. decemlineata'nın ergin bireyleri plastik petri kabı içerisinde bitki parçaları ile birlikte laboratuvara getirilmiştir. Laboratuvara getirilen ergin bireyler, pleksiglass kafes (30x50x60 $\mathrm{cm}$ boyutlarında, yanları ve üzeri tülle kaplı, pleksiglass malzemeden yapılmış kafes) içerisine daha önce yerleştirilmiş olan patates bitkileri ( $S$. tuberosum var Agria) üzerine bırakılmıştır. Böylece denemelerde, bu erginlerden oluşturulan kültürden alınan bireyler ve patates bitkisinden alınan yaklaşık olarak $10 \mathrm{~cm}$ uzunluğundaki yapraklı dal parçaları kullanılmıştır. Kesilen yapraklı dal parçası, tabanına kurutma kağıdı yerleştirilmiş olan $8 \times 8 \times 8 \mathrm{~cm}$ ebatlarındaki plastik kültür kabına alınmıştır. Sonra üzerine de 24 saat süreyle aç bırakılmış bir tane Patates böceği bireyi dikkatli bir şekilde yumuşak pens yardımıla konularak, 24 saat boyunca burada beslenmesi için bırakılmıştır. Yapraklı dal parçası, böceklerin beslenmesinden önce ve sonra hassas terazi (Kern ABC 220-4 $\mathrm{m}, \max =220 \mathrm{mg}, \min =10 \mathrm{mg}, \mathrm{e}=1 \mathrm{mg}, \mathrm{d}=0.1 \mathrm{mg}$ ) ile $\mathrm{mg}$ cinsinden tartılmıştır. $\mathrm{Bu}$ şekilde patates bitkisinden alınan yapraklı dal parçasında 24 saat içerisinde eksilen ağırlık miktarı belirlenmiştir.

Patates bitkisinden alınan yaklaşı olarak $10 \mathrm{~cm}$ uzunluğundaki yapraklı dal parçasının su kaybını belirlemek için yapraklı dal parçası aynı düzenek içerisinde bu defa Patates böceği bireyi konulmadan 24 saat boyunca bekletilmiş ve hem öncesinde hem de sonrasında $\mathrm{mg}$ cinsinden ağırlık tartımı yapılmıştır. $\mathrm{Bu}$ şekilde, bu iki tartım arasındaki fark hesaplanarak yapraklı dal parçasının su kaybı miktarı belirlenmiştir.

Hem Patates böceği kullanılarak hem de kullanılmadan yapılan denemeler $2^{\circ} \mathrm{C}$ lik artışlarla $17^{\circ} \mathrm{C}$ ile $35^{\circ} \mathrm{C}$ arasında olacak şekilde 10 farklı sıcaklıkta iklimlendirme dolabında (Protech ${ }^{\circledR}$ marka) her bir sıcaklık için ayrı ayrı olmak üzere 20 tekerrürlü olarak gerçekleştirilmiştir. Ayrıca denemeler L. decemlineata'nın II., III. ve IV. biyolojik dönemindeki larvaları ile ergin dönemindeki bireyleri için ayrı ayrı olmak üzere yürütülmüştür. Denemeler kurulurken, deri değişimi üzerinden 48 saat geçmiş bireylerin kullanılmasına özen gösterilmiştir. Bunun yanı sıra, zararlının I. dönemindeki larvaları, ancak biyolojik dönemin sonuna doğru ve çok az miktarda beslendiğinden dolayı yapraklı dal parçasından 24 saat içerisinde eksilen ağırlık miktarı çok az olmuş ve tüketim miktarının hesaplanması mümkün olmamıştır. Bu nedenle zararlının I. dönem larvaları dememelerde kullanılmamıştır.

\subsection{Denemelerin değerlendirilmesi}

Denemeler tesadüf parselleri deneme desenine göre kurulmuş ve 20 tekerrürlü olarak yürütülmüştür. Patates böceğinin 24 saat içerisindeki tüketim miktarı TM= AK - SK formülüne göre hesaplanmıştır. Formüldeki TM: tüketim miktarını, AK: Patates böceğinin 24 saatlik beslenmesi sonucu yapraklı dal parçasından eksilen ağırlık miktarını ve SK: Patates böceği beslenmesine maruz bırakılmadan 24 saatlik süre sonunda yapraklı dal parçasından eksilen su miktarını ifade etmektedir.

$\mathrm{Bu}$ şekilde hesaplanarak elde edilen tüketim miktarı verilerine ilk önce Shapiro-Wilk normallik testi uygulanmıştır. Parametrik olmadığı anlaşılan verilere karekök transformasyonu uygulandıktan sonra tek yönlü varyans analizine (One-Way ANOVA) tabi tutulmuş ve Tukey çoklu karşılaştırma testi (Tukey 1949) yapılmıştır. İstatistiksel analizler IBM ${ }^{\circledR}$ SPSS $^{\circledR}$ Statistics (Versiyon 20.0, Ağustos 2011, SPSS Inc., Chicago, Illinois, ABD) paket programı yardımıyla gerçekleştirilmiştir. 
Ayrıca farklı biyolojik dönemlerin sıcaklığa bağlı beslenme miktarlarının tanımlanması için Logan-10 matematiksel modellemesinden yararlanılmıştır. $\mathrm{Bu}$ modelin parametreleri aşağıdaki formül ile hesaplanmıştır (Logan ve ark. 1976; Logan 1988).

$$
d(T)=\alpha *\left[\left(1+k * e^{-p * T}\right)^{-1}-e^{(-(T \max -T) / \Delta T)}\right]
$$

Matematiksel modellemede, $d(T)$ : sıcaklığa bağlı tüketim miktarını, $\alpha$ : maksimum tüketim miktarı için $p$ katsayısı tarafından belirlenen asimptot değerini, $p$ : optimum sıcaklık oranını belirleyen katsayıyı, $T_{\max }$ : maksimum sıcaklığı ve $\Delta T$ : besin tüketiminin fizyolojik olarak teşvik edildiği sıcaklık aralığını ifade eder (Logan ve ark. 1976; Kontodimas ve ark. 2004). En yüksek tüketim miktarının sağlandığı sıcaklık değeri ise aşağıdaki formül ile hesaplanmıştır (Logan ve ark. 1976).

$$
T_{o p t}=T_{\max } *\left(1+\frac{\Delta T}{T_{\max }} * \frac{\ln (p * \Delta T)}{1-p * \Delta T}\right)
$$

Logan-10 matematiksel modellemenin parametrelerinin hesaplanması için SigmaPlot ${ }^{\circledR}$ (Versiyon 11.0, Systat Software, Inc., San Jose California, USA) paket programından yararlanılmıştır. Logan-10 matematiksel modelin eğrisinin sıcaklığa bağlı tüketim miktarı üzerine elde edilen verilere uygunluğunu belirlemek için belirleme katsayısı $\left(\mathrm{R}^{2}\right)$ ve artık kareler toplamı (RSS) değerleri kriter olarak kullanılmıştır (Kontodimas ve ark. 2004).

\section{Bulgular}

Leptinotarsa decemlineata'nın farklı biyolojik dönemlerinin farklı sabit sıcaklıklarda 24 saatlik süre içerisindeki tükettikleri besin miktarları Çizelge 1'de verilmiştir. Denemede kullanılan tüm sicaklıklarda $\left(17,19,21,23,25,27,29,31,33\right.$ ve $\left.35^{\circ} \mathrm{C}\right)$ en fazla besin tüketimi zararlının II. dönem larvalarında görülmüştür. Zararlının en az besin tüketimi gerçekleştiren biyolojik dönemi ise $33^{\circ} \mathrm{C}$ sicaklıkta yapılan denemeler haricinde IV. dönem larvaları olmuştur. Ayrıca tüketim miktarı arasındaki farklar istatistiksel olarak önemli bulunmuştur (Çizelge 1). Zararlının $33^{\circ} \mathrm{C}$ sicaklıkta yapılan denemelerde ise en az besin tüketimi ergin dönemdeki bireylerinde görülmüştür.

Leptinotarsa decemlineata'nın denemede kullanılan ergin dönemi hariç tüm biyolojik dönemleri en fazla beslenmeyi $29^{\circ} \mathrm{C}$ sıcaklıkta yapılan denemelerde gerçekleştirmişlerdir. Ergin dönemdeki bireyler ise en fazla besin tüketimini $27^{\circ} \mathrm{C}$ s1caklıkta göstermişlerdir. En az besin tüketiminin görüldüğü sicaklık ise tüm biyolojik dönemler için $17^{\circ} \mathrm{C}$ sıcaklık olmuştur (Çizelge 1).

$\mathrm{Bu}$ çalışmada ayrıca sıcaklığın $L$. decemlineata'nın farklı biyolojik dönemlerindeki tüketim miktarları üzerine etkisi, Logan-10 matematiksel modellemesi kullanılarak açıklanmıştır. Matematiksel modelin eğrisinin, sıcaklığa bağlı tüketim miktarı üzerine elde edilen verilere uygunluğunu belirlemek için belirleme katsayısı $\left(R^{2}\right)$ ve artık kareler toplamı $(R S S)$ değerleri kriter olarak kullanılmıştır (Kontodimas ve ark. 2004). Zararlının farklı biyolojik dönemlerinin farklı sıcaklıklara bağlı beslenme miktarlarına uygulanmış Logan-10 modeli eğrileri Şekil 1'de ve bu modele ait parametre değerleri Çizelge 2'de verilmiştir.

Leptinotarsa decemlineata'nın denemede kullanılan tüm biyolojik dönemlerindeki tüketim miktarları sıcaklıklarla birlikte bir miktar artış göstermiş ve $27.08-28.81^{\circ} \mathrm{C}$ sıcaklıklarda optimum seviyeye ulaşmıştır. Optimum seviyeye ulaşan tüketim miktarı sıcaklık artışının devamı ile birlikte azalmaya başlamıştır. Logan-10 modelinin zararlının tüm biyolojik dönemlerindeki bireylerinin sıcaklığa bağlı tüketim miktarı ile ilgili verilere uygunluk gösterdiği görülmüştür (Şekil 1 ve Çizelge 2).

Çizelge 1. Leptinotarsa decemlineata'nın farklı biyolojik dönemlerinin farklı sabit sıcaklıklarda 24 saatlik süre içerisinde tükettikleri besin miktarları (mg)

Table 1. The amount of food (mg) consumed by different biological periods of Leptinotarsa decemlineata in a 24-hour period at different fixed

\begin{tabular}{|c|c|c|c|c|}
\hline Sıcaklık & II. Dönem & III. Dönem & IV. Dönem & Ergin \\
\hline $17^{\circ} \mathrm{C}$ & $518.90 \pm 69.40 \mathbf{A ~ f ~}$ & $415.60 \pm 81.54 \mathbf{A B}$ e & $199.80 \pm 29.13 \mathbf{B ~ e}$ & $243.70 \pm 53.89$ B e \\
\hline $19^{\circ} \mathrm{C}$ & $788.65 \pm 65.52 \mathrm{~A}$ def & $550.30 \pm 60.11$ B de & $386.15 \pm 37.41$ B de & $485.15 \pm 75.28$ B de \\
\hline $21^{\circ} \mathrm{C}$ & $970.35 \pm 97.55$ A cde & $767.60 \pm 78.51$ AB bcde & $482.55 \pm 34.17$ C cd & $596.85 \pm 53.13 \mathbf{B C}$ cd \\
\hline $23^{\circ} \mathrm{C}$ & $1087.50 \pm 64.32$ A bcd & $907.40 \pm 115.97 \mathbf{A B}$ abc & $582.60 \pm 54.08 \mathrm{C}$ bcd & $724.95 \pm 61.86 \mathbf{B C}$ bcd \\
\hline $25^{\circ} \mathrm{C}$ & $1313.32 \pm 65.39 \mathbf{A ~ a b}$ & $1097.72 \pm 152.95$ AB abc & $711.22 \pm 96.56 \mathbf{B}$ abc & $850.52 \pm 84.97$ B bc \\
\hline $27^{\circ} \mathrm{C}$ & $1417.35 \pm 103.73 \mathrm{~A} \mathrm{a}$ & $1151.00 \pm 28.62 \mathrm{~A}$ abc & $849.05 \pm 70.36 \mathbf{B}$ a & $1157.55 \pm 64.98 \mathbf{A} \mathbf{a}$ \\
\hline $29^{\circ} \mathrm{C}$ & $1507.10 \pm 46.86 \mathbf{A} \mathbf{a}$ & $1187.50 \pm 44.30 \mathrm{~B}$ abc & $874.95 \pm 38.81 \mathbf{C a}$ & $1115.55 \pm 36.84 \mathbf{B}$ a \\
\hline $31^{\circ} \mathrm{C}$ & $1206.65 \pm 32.98$ A abc & $1004.35 \pm 40.08 \mathbf{B}$ ab & $797.30 \pm 41.31 \mathbf{C ~ a b}$ & $944.10 \pm 37.71 \mathbf{B}$ ab \\
\hline $33^{\circ} \mathrm{C}$ & $1010.85 \pm 53.77$ A bcde & $862.50 \pm 37.60 \mathrm{~A}$ abcd & $692.60 \pm 41.88 \mathbf{B}$ abc & $622.15 \pm 35.20 \mathrm{~B} \mathrm{~cd}$ \\
\hline $35^{\circ} \mathrm{C}$ & $736.65 \pm 31.28 \mathrm{~A}$ ef & $568.65 \pm 43.91$ B cde & $424.90 \pm 43.19 \mathbf{C ~ d e}$ & $529.70 \pm 34.64 \mathbf{B C ~ d}$ \\
\hline
\end{tabular}
temperatures.

*Aynı satırda farklı büyük harfleri ve aynı sütunda farklı küçük harfleri taşıyan ortalamalar ( \pm standart hatalar) arasındaki farklar istatistiksel olarak önemlidir (Tukey’s HSD test, $P>0.05 ; \mathrm{n}=20$ ).

*Different uppercase letters in the same row and different lowercase letters in the same column indicate a statistically significant difference among the amounts of food consumed ( \pm standard errors) (Tukey's HSD test, $P>0.05 ; \mathrm{n}=20$ ). 

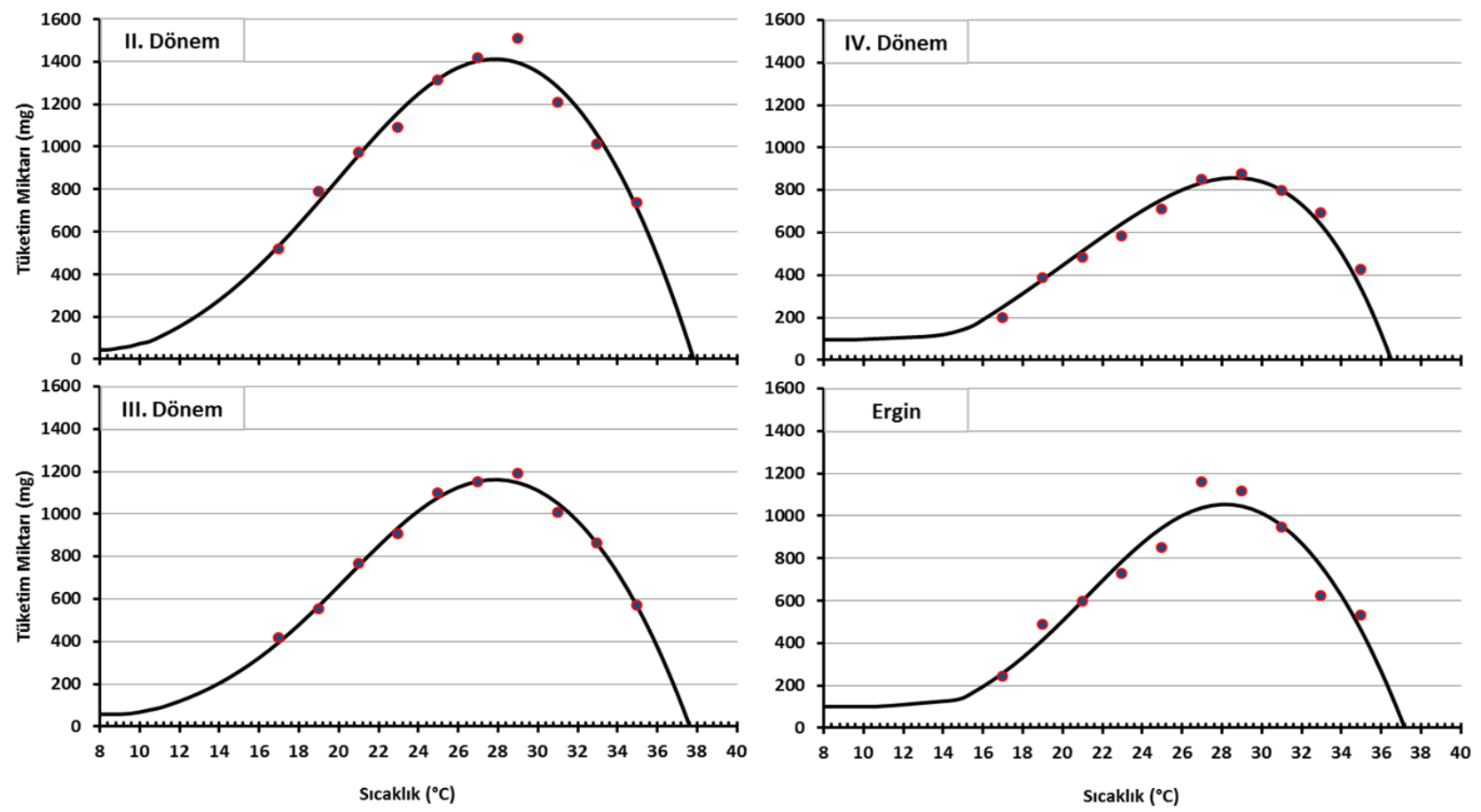

Şekil 1. Leptinotarsa decemlineata (Say.)'nın farklı biyolojik dönemlerinin farklı sabit sıcaklıklarda 24 saatlik süre içerisinde tükettikleri besin miktarları (mg) üzerine uygulanmış Logan-10 modeli eğrileri.

Figure 1. The Logan-10 model curves applied on the amount of food $(\mathrm{mg})$ consumed by different biological periods of Leptinotarsa decemlineata (Say.) in a 24-hour period at different fixed temperatures.

Çizelge 2. Leptinotarsa decemlineata'nın farklı biyolojik dönemlerinin farklı sabit sıcaklıklarda 24 saatlik süre içerisinde tükettikleri besin miktarları (mg) üzerine uygulanmıș Logan-10 modelinin parametreleri

Table 2. Parameters of the Logan-10 model applied on the amount of food $(\mathrm{mg})$ consumed by different biological periods of Leptinotarsa decemlineata in a 24-hour period at different fixed temperatures

\begin{tabular}{lcccc}
\hline Parametreler* & II. Dönem & III. Dönem & IV. Dönem & Ergin Dönemi \\
\hline $\boldsymbol{\alpha}$ & $3994.495 \pm 787.492$ & $2401.353 \pm 172.692$ & $14208.524 \pm 710.467$ & $2565.500 \pm 958.971$ \\
\hline $\boldsymbol{k}$ & $57.720 \pm 3.463$ & $134.480 \pm 6.282$ & $23.171 \pm 2.454$ & $184.858 \pm 8.967$ \\
\hline $\boldsymbol{\rho}$ & $0.185 \pm 0.332$ & $0.225 \pm 0.268$ & $0.100 \pm 0.123$ & $0.231 \pm 0.470$ \\
\hline $\boldsymbol{T}_{\max }$ & $37.87 \pm 4.936$ & $37.57 \pm 2.781$ & $37.18 \pm 2.812$ & $37.54 \pm 3.634$ \\
\hline$\Delta \boldsymbol{T}$ & $11.44 \pm 3.862$ & $8.65 \pm 2.108$ & $15.56 \pm 5.476$ & $9.41 \pm 3.354$ \\
\hline $\boldsymbol{T}_{\text {opt }}$ & 27.99 & 27.08 & 28.81 & 28.31 \\
$\boldsymbol{R}^{2}$ & 0.968 & 0.991 & 0.989 & 0.919 \\
\hline $\boldsymbol{R S S}$ & 2038.765 & 5807.604 & 5109.481 & 6121.34 \\
\hline
\end{tabular}

*Modele ait $\alpha, k, \rho, T_{\max }$ ve $\Delta T$ parametrelerinin değerleri, standart hataları ile birlikte verilmiştir $(P<0.0001)$.

$*$ The values of the parameters $\alpha, k, \rho, T_{\max }$ and $\Delta T$ of the model are given with their standard errors $(P<0.0001)$

\section{Tartışma ve Sonuç}

Leptinotarsa decemlineata (Say.) (Coleoptera: Chrysomelidae)'nın farklı biyolojik dönemlerindeki bireyleri ve 10 farklı sıcaklıklardaki $\left(2^{\circ} \mathrm{C}\right.$ lik artışlarla $17^{\circ} \mathrm{C}$ ile $35^{\circ} \mathrm{C}$ arasında) 24 saatlik beslenme miktarı üzerine yapılan bu çalışmanın sonucunda, biyolojik dönemler içerisinden en fazla besin tüketimini II. dönem larvaların gerçekleştirdiği görülmüsşür. Zararlının II. dönem larvalarını tüketim miktarı bakımından III. dönemdeki larvalar takip etmiştir. En az tüketim gösteren bireyler, $33^{\circ} \mathrm{C}$ haricindeki tüm sicaklıklarda, IV. dönemdeki larvalar olmuş ve $33^{\circ} \mathrm{C}$ 'de ise en az tüketimi ergin dönemdeki bireyler göstermiştir. Ancak, Logan ve ark. (1985) $L$. decemlineata larvalarının sıcaklığa bağlı gelişimi ve beslenmesi üzerine yapmış olduğu bir çalışmada, IV. dönem larvaların diğer dönemlere göre daha fazla beslendiğini bildirmişlerdir. Zararlının IV. dönem larvalarının beslenme miktarındaki farklılığın nedeninin, bu dönemde larvaların beslenme davranışından kaynaklandığı düşünülmektedir. Holometabol başkalaşım gösteren Patates böceğinin IV. dönem larvaları en fazla 2-3 gün kadar aktif beslenme davranışı göstermekte daha sonra toprakta pupa olmaktadır. Ancak pupa olmadan önce yaklaşık iki gün boyunca beslenme davranış1 göstermemektedir. $\mathrm{Bu}$ nedenle de IV. dönemdeki larvaların besin tüketim miktarında farklılıklar görülebilmektedir. Gerek entomofag gerekse fitofag böceklerin tüketim miktarı üzerine biyolojik dönemlerin etkisi farklı araştırmacılar tarafindan merak konusu olmuştur. Örneğin, Sopp ve Wratten (1986) laboratuvar ortamında bazı fitofag avcıların tahıl yaprakbiti (Schizaphis graminum (Rondani) (Hemiptera: Aphididae)) tüketim oranları üzerine yaptıkları bir çalışmada tüketim miktarındaki artışlar böceklerin vücut ağırlığı ile doğru orantılı olarak arttığını belirtmişlerdir. Ayrıca dişi bireylerin tüketim oranları erkek bireylerin tüketim oranlarından daha fazla 
olduğunu bildirmişlerdir. Yu ve ark. (2013) Aphis gossypii Glover. (Hemiptera: Aphididae) üzerinde beslenen Harmonia dimidiata (F.) (Coleoptera: Coccinellidae)'nı farklı sıcaklıklardaki beslenmesi üzerine yaptığı bir çalışmasında, ergin bireylerin yaprakbiti tüketiminin, larvaların yaprakbiti tüketiminden fazla olduğunu belirtmiştir. Erkek ve dişi bireylerin en fazla yaprakbiti tüketimi, sırasıyla 1969.0 ve 1835.5 adet olarak $25^{\circ} \mathrm{C}$ 'de olduğu saptanmıştır. Birgücü ve Karsavuran (2013) Nezara viridula (L.) (Hemiptera: Pentatomidae)'nın fasulye baklasındaki zarar miktarı üzerine yaptığı bir çalışmada en fazla zararı $\mathrm{V}$. nimf ve preovipozisyon dönemindeki bireylerin, en az zarar1 ise III. ve IV. nimf dönemindeki bireylerin yaptığını belirtmişlerdir. Akman Gündüz ve Gülel (2002) Schistocerca gregaria Forsk. (Orthoptera: Acrididae)'nın besin tüketimi üzerine sıcaklığın etkisi ile ilgili yapıkları bir çalışmada, ergin bireylerin besin tüketiminin sıcaklık arttıkça ergin olduktan sonraki ilk haftada arttığını, ilk haftanın sonundan cinsel olgunlaşma süresine kadar ise tüketim miktarında azalma olduğunu bildirmiştir. Yapılan bu çalışmanın ve daha önceki çalışmaların sonuçlarından anlaşılacağ gibi böceklerin biyolojik dönemlerindeki beslenme davranışı ve fizyolojik farklılıklarına göre besin tüketim miktarlarında da değişimler olduğu kanaatine varılmıştır.

Yapılan bu çalışmada Patates böceği'nin tüm biyolojik dönemlerinde sıcaklık artıkça tüketim miktarının arttığı görülmüştür. Ancak yaklaşı $27.08-28.81^{\circ} \mathrm{C}$ sicaklıklardan sonra yine tüm biyolojik dönemlerde tüketim miktarı azalmaya başlamıştır. $\mathrm{Bu}$ sonuçlara dayanarak, sicaklığın Patates böceğinin besin tüketimi üzerine etkisinin olduğu kanaatine varılmıştır. Sıcaklığın böceklerin gelişimi ve besin tüketimi üzerine etkisi ile ilgili çok çalışma bulunmaktadır. Logan ve ark. (1985) L. decemlineata larvalarının beslenmesi üzerine sıcaklığın etkisini araştırdıkları çalışmada, sıcaklığın zararlının besin tüketimini etkilediğini ifade etmişlerdir. Yanık (2011) 25 ve $30^{\circ} \mathrm{C}$ sicaklikta Oenopia conglobata (L.) (Coleoptera: Coccinellidae)'nın tüm larva dönemlerinin Ephestia kuehniella Zell. (Lepidoptera: Pyralidae) yumurtaları üzerinde tükettikleri toplam yumurta sayısını sirasiyla 565.40 ve 595.90 adet olarak bildirmiştir. Çalışma sonucunda ise $O$. conglobata'nın birer tane dişi ve erkek bireyin tükettiği E. kuehniella yumurtalarında sıcaklığın bir etkisinin olmadığını belirtmişlerdir. Manrique ve ark. (2012) Aulacaspis yasumatsui (Hemiptera: Diaspididae) ile beslenen Phaenochilus kashaya (Coleoptera: Coccinellidae)'nın tüketiminde sıcaklığın etkisi üzerindeki yaptığı bir çalışmasında, en yüksek beslenmenin $20^{\circ} \mathrm{C}$ 'de gerçekleştiğini ve biyolojik dönemler içinden IV. dönem larvaların daha fazla beslendiğini bildirmişlerdir. Schwarz ve Frank (2019) bazı Coccinellidae türleri üzerinde sıcaklığın Acyrthosiphon pisum (Hemiptera: Aphididae) tüketimi üzerine yaptığı çalışmada Coccinella septempunctata (Coleoptera: Coccinellidae) larvalarının yüksek sıcaklıklarda ergin bireye göre daha fazla yaprakbiti ile beslendiğini ileri sürmüşlerdir. Ayrıca ergin bireylerdeki vücut ağırlığı değişimininde artan sıcaklıkların bir etkisi olmamıştır. Krengel ve ark. (2013) C. septempunctata ve Harmonia axyridis (Pallas) (Coleoptera: Coccinellidae'nın besin tüketimine yüksek sıcaklığın etkisi üzerine yaptıkları bir çalışmada, her iki coccinellid türünün de yüksek sıcaklıklarda önemli ölçüde daha fazla yaprakbiti (Sitobion avenae (F.) (Hemiptera: Aphididae)) tükettiğini bildirmişlerdir. Genellikle de $C$. septempunctata'nın ergin döneminin ilk 10 günü boyunca $H$. axyridis'den daha fazla yaprakbiti tükettiğini ifade etmişlerdir. Ayrıca C. septempunctata dişilerinin sadece normal sicaklıkta erkek bireylere göre daha obur davrandığını ancak $H$. axyridis dişilerinin ise her iki sıcaklıkta da erkek bireylerden önemli derecede daha fazla yaprakbiti tüketimi gerçekleştirmiş olduğunu ileri sürmüşlerdir. Kamal ve ark. (2013) Aulacophora foveicollis (L.) (Coleoptera: Chrysomelidae)'in beslenmesinde konukçu bitkinin ve sıcaklıkların etkisi üzerine yaptığı bir çalışmasında, zararlının artan sıcaklıklarla birlikte kabak türleri üzerinde daha fazla beslendiğini ifade etmişlerdir.

$\mathrm{Bu}$ çalışmada, L. decemlineata'nın farklı biyolojik dönemlerdeki bireylerinin 10 farklı sıcaklıkta $\left(2^{\circ} \mathrm{C}\right.$ 'lik artışlarla $17^{\circ} \mathrm{C}$ ile $35^{\circ} \mathrm{C}$ arasında) ve 24 saat içerisindeki tüketim miktarları üzerine uygulanan Logan-10 modeli eğrisine ve parametrelerine göre, zararlının tükettiği patates bitkisinin yapraklı dal parçası miktarı, belli bir sıcaklığa kadar artış göstermiş ve optimum sicaklığa $\left(27.99-28.81^{\circ} \mathrm{C}\right)$ ulaştıktan sonra tüketim miktarının azalarak sıfira kadar $\left(37.18-37.87^{\circ} \mathrm{C}\right)$ düştüğü görülmüştür. Lactin ve ark. (1993) yaptıkları bir çalışmada $L$. decemlineata larvalarının beslenme miktarının en yüksek olduğu sıcaklığının $29^{\circ} \mathrm{C}$ 'de gerçekleştiğini bildirmişlerdir. Ferro ve ark. (1985) L. decemlineata'nın sıcaklığa bağlı beslenme ve gelişim oranları üzerine yaptığı bir çalışmaya göre $15^{\circ} \mathrm{C}$ 'de tüm larva dönemlerinin ve ergin bireyin tüketim oranları yaklaşık olarak sırasıyla $0.2,1.5,3.0$ ve $1.0 \mathrm{~cm}^{2}$ gün ${ }^{-1}$ olarak belirlemişlerdir. Ayrıca sıcaklık $33^{\circ} \mathrm{C}^{\prime}$ ye doğru yükseldikçe, I. ve II. dönem larvaların beslenmelerinin arttığını, diğer dönemlerin ise optimum sicaklıktan sonra $\left(28^{\circ} \mathrm{C}\right.$ 'den $30^{\circ} \mathrm{C}$ 'ye kadarki sicaklıklarda) beslenmelerinin azaldığını bildirmişlerdir ki, bu da bu çalışmada elde edilen verilerle paralellik göstermektedir. Lemoine ve ark. (2014), herbivor böceklere sıcaklığın etkilerinin modellemesini yaparak açıkladıkları bir çalışmada Lepidoptera, Coleoptera ve Hymenoptera takımlarından 14 farklı böcek türü ve 12 adet bitki çeşidi kullanmışlar ve denemeleri $20,25,30$ ve $35^{\circ} \mathrm{C}$ sıcaklıklarda gerçekleştirmişlerdir. Tüketim miktarının $20^{\circ} \mathrm{C}$ ile $30^{\circ} \mathrm{C}$ arasında, sıcaklık artışıyla birlikte artı̆̆ını, ancak daha sonra artış göstermediğini hatta azalışa geçtiğini ifade etmişlerdir. Ayrıca sıcaklığa bağlı besin tüketimindeki artışın konukçu bitkiye göre değiştiğini bu yüzden bazı herbivor böceklerin sıcaklık artışına tepkilerinin kendine özgü bir şekilde gerçekleştiğini bildirmişlerdir. Sonuç olarak herbivor böceklerin besin tüketimi üzerine sıcaklığın etkisinin olduğunu ve böcek-konukçu bitki etkileşimine göre sıcaklığın etkisinin değiştiğini belirtmişlerdir. Logan ve ark. (1985) L. decemlineata larvalarının besin tüketimi üzerine sıcaklığın etkisini araştırdıkları bir çalışmada, sıcaklığın etkisi üzerine Logan-10 modelini uygulamışlar ve bu çalışmadaki sonuçlara benzer şekilde sıcaklık arttıkça besin tüketiminin arttığını ancak belli bir sıcaklıktan sonra azalışa geçtiğini, $35^{\circ} \mathrm{C}$ 'nin hemen üzerindeki bir sicaklıkta modellemeye göre beslenmenin olmadığını ileri sürmüşlerdir.

Sonuç olarak bu çalışma göstermiştir ki, L. decemlineata'nın beslenme miktarı üzerine hem biyolojik dönemlerinin hem de sıcaklığın etkisi bulunmaktadır. Zararlının biyolojik dönemleri içerisinde en fazla besin tüketimi II. dönemdeki larvalarda, en az tüketim ise IV. dönem larvalarda bulunmuştur. Ayrıca sıcaklığa bağlı tüketim miktarları üzerine uygulanan Logan-10 modeli eğrisine ve parametrelerine göre zararlı için en yüksek beslenmenin gerçekleştiği optimum sıcaklığın $27.99-28.81^{\circ} \mathrm{C}$ olduğu ve $37^{\circ} \mathrm{C}$ civarında besin tüketiminin olmadığı saptanmıştır. Bu çalışma sonucunda, zararlının popülasyonundaki ve zarar miktarındaki mevsimsel değişim ve dolayısıyla bu zararlıya karşı uygulanacak mücadele yöntemleri üzerine yapılacak ileriki çalışmalar için önemli veriler elde edildiği düşünülmektedir. 


\section{Teşekkür}

$\mathrm{Bu}$ çalı̧̧ma Isparta Uygulamalı Bilimler Üniversitesi, Fen bilimleri Enstitüsü, Bitki Koruma Anabilim Dalı'nda hazırlanan birinci yazarın yüksek lisans tezinin bir bölümüdür.

\section{Kaynaklar}

Akman Gündüz NE, Gülel A (2002) Effect of temperature on development, sexual maturation time, food consumption and body weight of Schistocerca gregaria Forsk. (Orthoptera: Acrididae). Turkish Journal of Zoology 26(2): 223-227.

Atak U (1973) Trakya Bölgesinde Patates böceği (Leptinotarsa decemlineata Say.)'nin morfolojisi, bio-ekolojisi ve savaş metotları üzerinde araştırmalar. Tarım Bakanlığı Zirai Mücadele ve Zirai Karantina Genel Müdürlüğü Yayınları, Teknik Bülten 6 .

Birgücü AK, Karsavuran Y (2013) Nezara viridula (L) (Hemiptera: Pentatomidae'nın fasulye baklasındaki zarar miktarı üzerine araştırmalar. Türkiye Entomoloji Dergisi 37(3): 375-388.

Çam H, Gökçe A, Kadıŏlu İ, Yanar Y, Demirtaș İ, Gören N, Whalon ME (2012) Bitki ekstratlarının Patates böceği [Leptinotarsa decemlineata Say (Coleoptera: Chrysomelidae)]'nin farklı dönemleri üzerine mide zehiri ve rezidüyel toksisite etkileri. Türkiye Entomoloji Dergisi 36(2): 249-254.

Dolezal P, Habustova O, Sehnal F (2007) Effects of photoperiod and temperature on the rate of larval development, food conversion efficiency, and imaginal diapause in Leptinotarsa decemlineata. Journal of Insect Physiology 53(8): 849-847.

Ferro DN, Logan JA, Voss RH, Elkinton S (1985) Colorado potato beetle (Coleoptera: Chrysomelidae) temperature-dependent growth and feeding rates. Environmental Entomology 14(3): 343-348. doi: 10.1093/ee/14.3.343.

Kamal MM, Uddin MM, Shajahan M, Rahman MM (2013) Role of host and temperature on the feeding and oviposition behaviour of red pumpkin beetle Aulacophora foveicollis (Lucas). Progressive Agriculture 24(1-2): 53-60.

Kekillioğlu A, Yılmaz M (2018) Patates böceği [Leptinotarsa decemlineata Say. (Coleoptera: Chrysomelidae)]'nın Nevşehir ilinde yaşamsal etkileșim ve cesitliliği üzerine bir ön çalıșma. Anadolu Ege Tarımsal Araştırma Enstitüsü Dergisi 28: 100-107.

Kontodimas DC, Eliopoulos PA, Stathas GJ, Economou LP (2004) Comparative temperature-dependent development of Nephus includens (Kirsch) and Nephus bisignatus (Boheman) (Coleoptera: Coccinellidae), preying on Planococcus citri (Risso) (Homoptera: Pseudococcidae): Evaluation of a linear and various non-linear models using specific criteria. Environmental Entomology 33: 1-11.

Kostik M, Stankovic S, Kuzevski J (2016) Role of ache in Colorado potato beetle (Leptinotarsa decemlineata Say) resistance to carbamates and organophosphates. In: Trdan S (Ed), Insecticides Resistance, pp. 19-40. doi: 10.5772/61460.

Krengel S, Richter C, Freier B, Stangl GI, Brandsch C (2013) The effect of elevated temperatures on food conversion efficiencies of Coccinella septempunctata and Harmonia axyridis young adults feeding on Sitobion avenae. Journal of Plant Diseases and Protection 120(5/6): 218-226. doi:10.1007/BF03356478.

Lactin DJ, Holliday NJ, Lamari LL (1993) Temperature dependence and constant-temperature diel aperiodicity of feeding by Colorado potato beetle larvae (Coleoptera: Chrysomelidae) in short-duration laboratory trials. Environmental Entomology 22: 784-790. doi: 10.1093/ee/22.4.784.

Lemoine NP, Burkepile DE, Parker JD (2014) Variable effects of temperature on insect herbivory. The Journal of Life and Environmental Sciences 2: 376.

Logan JA, Wollkind DJ, Hoyt SC, Tanigoshi LK (1976) An analytic model for description of temperature dependent rate phenomena in arthropods. Environmental Entomology 5: 1133-1140.

Logan JA (1988) Toward an expert system for development of pest simulation models. Environmental Entomology 17: 359-376.

Logan PA, Casagrande RA, Faubert HH, Drummond AA (1985) Temperature-dependent development and feeding of immature Colorado potato beetles, Leptinotarsa decemlineata (Say.) (Col.: Chrysomelidae). Environmental Entomology 14: 275-283.

Manrique V, Mancero-Castillo DA, Cave RD, Nguyen R (2012) Effect of temperature on the development and consumption of Phaenochilus kashaya (Coleoptera: Coccinellidae), a predator of the cycad aulacaspis scale, Aulacaspis yasumatsui. Biocontrol Science and Technology 22(11): 1245-1253.

Neal JJ, Plaisted RL, Tingey WM (1991) Feeding behavior and survival of Colorado potato beetle, Leptinotarsa decemlineata (Say.), larvae on Solanum berthaultii Hawkes and an $\mathrm{F}_{6}$ S. tuberosum L. XS. berthaultii hybrid. American Potato Journal 68: 649-658.

Noronha C, Cloutier C (2006) Effects of potato foliage age and temperature regime on prediapause Colorado potato beetle Leptinotarsa decemlineata (Coleoptera: Chrysomelidae). Environmental Entomology 35(3): 590-599.

Schwarz T, Frank T (2019) Aphid feeding by lady beetles: higher consumption at higher temperature. Biological Control 64(3): 323332 .

Sopp P, Wratten SD (1986) Rates of consumption of cereal aphids by some polyphagous predators in the laboratory. Entomologia Experimentalis et Applicata 41(1): 69-73. doi: 10.1111/j.15707458.1986.tb02173.x.

TÜIK (2019) Türkiye İstatistik Kurumu https://www.tarimorman.gov.tr/sgb/Belgeler/SagMenuVeriler/BUG EM.pdf. Erişim 02 Ağustos 2019.

Tukey JW (1949) Comparing individual means in the analyses of variance. Biometrics 5: 99-114.

Yabaş C, Ulubilir A, Canhilal R (1995) Patates böceği [Leptinotarsa decemlineata say (Col.:Chrysomelidae)]'nin biyolojik mücadelesi üzerinde bazı araștırmalar. Bitki Koruma Bülteni 35: 3-4.

Yanık E (2011) Farklı sicaklıkların Ephestia kuehniella Zell. (Lepidoptera: Pyralidae) yumurtalarında beslenen Oenopia conglobata (L.) (Coleoptera: Coccinellidae)'nın biyolojik özelliklerine etkisi. Harran Üniversitesi Ziraat Fakültesi Dergisi 15(1): 21-28.

Yu J, Chi H, Chen BH (2013) Comparison of the life tables and predation rates of Harmonia dimidiata (F.) (Coleoptera: Coccinellidae) fed on Aphis gossypii Glover (Hemiptera: Aphididae) at different temperatures. Biological Control 64(1): 1-9. 